\title{
Oficinas de Criatividade: atendimento à população de rua ${ }^{\star}$
}

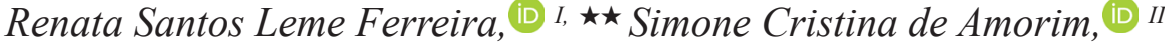 \\ Letícia Geraldo Firmino, (D) III Isabela Cristina Ortiz Gambaro (DIV \\ ${ }^{I}$ Universidade Paulista, Sorocaba, SP, Brasil \\ ${ }^{\text {II }}$ Universidade Estadual de Campinas, Campinas, SP, Brasil \\ III Associação Brasileira de Psicodrama e Sociodrama, São Paulo, SP, Brasil \\ ${ }^{I V}$ Centro de Estudos de Terapias Naturais, Sorocaba, SP, Brasil \\ Resumo
}

O presente trabalho é um relato de experiência do estágio curricular de Oficina de Criatividade, realizado com população de rua. Esta modalidade de intervenção visa atender populações que normalmente estão à margem dos serviços tradicionais de psicologia. Utiliza técnicas expressivas como meio de acesso às experiências humanas e sua finalidade é favorecer a transformação das relações e ampliar o horizonte existencial de cada integrante. A perspectiva teórica adotada a respeito do trabalho com população de rua pressupõe o distanciamento da patologização dos comportamentos desviantes e moralmente estabelecidos e prioriza a valorização, a aproximação e o reconhecimento dos diferentes modos de ser e estar no mundo. A experiência aqui descrita atendeu a este propósito na medida em que os participantes puderam refletir e compartilhar seus saberes, histórias e cultura, sentindo-se valorizados para reconhecer ou construir e comunicar seu posicionamento crítico a respeito de certa institucionalização concreta e cultural dos serviços socioassistenciais e psicológicos direcionados a este público. Desde modo, entendemos que a Oficina de Criatividade favoreceu mútuas afetações entre pesquisador, pesquisado e instituição, num exercício de ressignificação sobre o fazer psicológico e seu potencial transformador.

Palavras-chave: Psicologia; Oficina de Criatividade; população de rua.

\section{Creativity Workshop: service to the homeless population}

\section{Abstract}

This work is a traineeship experience report of Creativity Workshop, conducted with homeless people. This type of intervention needs to serve populations that are frequently beyond the traditional psychology services. Uses expressive techniques as a means to human experience and its purpose is to promote the transformation of relationships and expand the existential horizon of each participant. The theoretical perspective adopted about work with homeless people sought to distance from the pathologizing of different behavior and morally established and prioritize the valuation, approximation and recognition of different ways of being in the world. The experience described here has served this purpose insofar as the participants were able to reflect and share their knowledge, histories and culture, feeling appreciated recognizing or constructing and communicating their critical position regarding a certain concrete and cultural institutionalization of social welfare and psychological services directed to this public. Thus, we understand that the Creativity Workshop favored common affectations between researcher, researched and institution, in an exercise of ressignification about the psychological doing and its transforming potential.

Keywords: Psychology; Workshop Creativity; homeless population.

\section{Por que Oficinas de Criatividade?}

Antes de iniciarmos o relato da experiência, apresentaremos alguns aspectos a respeito do clima intelectual e cultural de nosso contexto social e o motivo pelo qual a Oficina de Criatividade foi selecionada como intervenção para o contexto da instituição em que realizamos o estágio.

Vivemos em uma época em que impera o pensar e o agir tecnicista. Há uma demanda pelo cumprimento de tarefas fragmentadas e automáticas, exige-se a precisão e a exatidão do gesto e do discurso, de forma que, neste contexto, os modos de pensar e agir já estão determinados (OSTRONOFF; FÁVERO; BALDIN, 2008, p. 87-88).

\footnotetext{
^O presente trabalho é um relato da experiência de estágio curricular com Oficina de Criatividade, disciplina e estágio inseridos no curso de Psicologia da Universidade Paulista, na cidade de Sorocaba, no ano de 2012. No último ano do curso de Psicologia da UNIP, os alunos devem realizar três estágios obrigatórios, há três eixos temáticos. Devem optar por um estágio em cada eixo; cada eixo possui quatro opções de estágio em diferentes modalidades com disciplinas correspondentes. $\mathrm{O}$ presente trabalho se refere ao eixo Práticas Psicológicas em Contexto Específico, disciplina de Intervenções Psicoeducativas, como estágio na modalidade de Oficina de Criatividade.

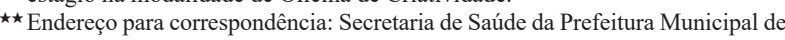
Araçariguama. Alameda 19 de Maio, 02, Centro - Araçariguama, São Paulo, SP - Brasil. CEP: 18147-000.E-mails: renata.s.l.ferreira@hotmail.com, sim.psicologa@gmail.com, leticiafirmino@hotmail.com, isabelacogambaro@gmail.com Os dados completos das autoras encontram-se ao final do artigo.
}

Sendo assim, o homem é adestrado para corresponder a esses apelos em diversos âmbitos da existência, nos quais suas vivências são negligenciadas e não elaboradas. Não são privilegiados os espaços para a reflexão e a apropriação de significados particulares. Os conhecimentos são transmitidos de acordo com a lógica do especialista e os fatos são limitados pela explicação correspondente.

As abordagens psicológicas envolvidas por este invólucro sócio-histórico-cultural acabam por atender às demandas tecnicistas, de modo a reproduzir as práticas que prezam por classificações e determinações patológicas, o que se dá em função do controle e da exclusão; assim, os humanos passam a ser formados para servirem de peças de reposição que não devem sentir (CUPERTINO, 2007, p. 8-9; 2008, p. 2).

A partir dessa visão crítica, surge uma nova modalidade de fazer psicológico, a Oficina de Criatividade, desenvolvida por Cupertino e seus alunos, como alternativa a esse modelo, ao perceberem que as práticas psicológicas tradicionais não atendiam à demanda da população situada tradicionalmente à margem dos serviços psicológicos. 
A Oficina de Criatividade é dirigida ao público cujo acesso aos serviços psicológicos é escasso. Ocorre através de encontros grupais, que estimulam seus participantes ao uso de diversas formas de expressão, para, a partir do próprio grupo, lidar de maneira individualizada com os temas emergentes (CUPERTINO, 2008, p. 2). São utilizadas técnicas expressivas como meio de acesso às experiências humanas, de modo a compreendê-las e, se necessário, dar continência e alívio ao sofrimento. Tal prática tem a finalidade de favorecer as transformações das relações e ampliar o horizonte existencial de cada integrante, isto por meio da experiência e vivência compartilhada e do reconhecimento da diversidade de formas de existir (CUPERTINO, 2008, p. 2). Assim, os indivíduos são projetados para vivências, tempos e espaços diversos, promovendo o estabelecimento de redes de entendimento e solidariedade, com uma psicologia mais voltada para o devir, empenhada em colocar em movimento o que está cristalizado e não em diagnosticar e ajustar os desvios (CUPERTINO, 2007, p. 3).

Este trabalho promove ressignificações, pois, ao entrar em contato com o que estava oculto em si mesmo, o participante reorganiza e vivencia de maneira diferente suas questões relacionadas ao tema proposto. $\mathrm{O}$ intuito é o apropriar-se do sentido da experiência, explorar a imaginação e contemplar alternativas (CUPERTINO, 2008, p. 6) a partir da troca com os outros.

O foco se concentra no fortalecimento das relações e no estabelecimento de redes de apoio e sustentação, promovendo a autonomia dos integrantes, para que eles mesmos assumam este processo de autoexploração, onde o psicólogo se constitui apenas como um facilitador (CUPERTINO, 2008, p. 9).

Distante do caráter de determinação de posições hierárquicas em relação à detenção do saber, as oficinas de criatividade servem para compor uma visão multidimensional da problemática posta em questão, permitindo que as finalidades mencionadas acima ocorram num contexto de afetação mútua (CUPERTINO, 2007, p. 11).

Deste modo, entende-se que o grupo é o determinante da oficina, é dele que partirá o clima, a intuição e a percepção do que está para se desvelar. ${ }^{1}$ A atividade proposta deve ser colocada do modo mais vago possível, para que cada pessoa expresse o que se apresenta como questão para ela naquele momento (CUPERTINO, 2008, p. 5-6). Geralmente, no aquecimento do grupo, o tema do dia emerge, não pode ser definido de antemão, apenas planejado de maneira descartável, aberta ao presente e aos imprevistos que pedem expressão (CUPERTINO, 2008, p. 10-11).

\footnotetext{
Desvelamento. 1. Em Platão, a verdade (aletheia) significa desvelamento do ser isto é, descobrimento daquilo que estava oculto, retirada do véu. 2 . Na metafísica de Heidegger, o desvelamento significa a ideia segundo a qual o ser da coisa se desvela, manifesta-se nas condições mesmas de seu aparecer, de seu "fenômeno", a verdade nada mais sendo que a manifestação do ente e do caráter aberto do ser, enquanto ele deixa de ser ocultado pelas preocupações da vida cotidiana (JAPIASSÚ; MARCONDES, 2008). Em nossas oficinas partimos da compreensão de desvelamento fenomenológica utilizada por Cupertino (2007), que designa o aparecimento, desenvolvimento e contato mais explícito no ser-aí, a partir da suspensão de significados prematuros, das categorias preestabelecidas e familiares, numa aproximação com a experiência e o significado emergente em si e no mundo.
}

A experimentação de outras sensibilidades é sempre acompanhada de angústias e incertezas, tendo em vista que rompem com a moral ${ }^{2}$ impregnada no nosso modo de pensar e agir (ANDRADE, 2008, p. 70). Contudo, quando essas experiências são compartilhadas no grupo, são também sentidas e acolhidas em sua propriedade. Aquilo que era percebido como ameaçador passa a ser acolhido como próprio e singular, aumentando a potência de agir. Esta experiência propicia um primeiro contato com a suspensão da fala racional e sistematizada, num mergulho na falta de sentido imediato e na construção gradativa de significados múltiplos das experiências vividas, ao mesmo tempo em que acolhe a multiplicidade e a singularidade que atravessam cada participante. Esta suspensão inicial propicia que surja uma revisão das situações e atitudes vividas no cotidiano, com a possibilidade de transformá-las (ANDRADE, 2008, p. 73).

Este rompimento com a moral (ANDRADE, 2008, p. 70) está diretamente relacionado com a construção dos sentidos a partir do vivido, a fala poética (CUPERTINO, 2008, p. 2-6), a qual preconiza a suspensão de significados prematuros, que nos fornecem a sensação de reasseguramento, priorizando o sentido emergente na e da experiência, abrindo a possibilidade de ressignificar aspectos cristalizados. Sendo assim, é exigida uma postura de suspensão dos significados do oficineiro, numa abertura para o encontro com as afetações e transformações advindas deste mesmo encontro.

Todavia o foco não deve se restringir ao sofrimento ou aos problemas pessoais, mas estar direcionado a tudo que se dê neste encontro, a partir dos recursos oferecidos e com os participantes que tenham interesse em integrar o processo. Cabe ao oficineiro, então, a criação de um espaço de acolhida para a demanda, para que o participante viva a experiência da forma que desejar, como ele quiser que ela se dê (CUPERTINO, 2008, p. 11).

O papel do oficineiro é duplo, precisa estar atento à demanda grupal com os temas que emergem do grupo no próprio encontro e às expressões singulares dos participantes, de uma forma mais individualizada, mas não pessoalmente afunilada. O psicólogo nesta função é um descobridor dos arranjos viáveis de atendimento, numa contínua construção conjunta de significados para o que é vivenciado, favorecendo encontros transformadores (CUPERTINO, 2007, p. 6). Para o psicólogo há a necessidade de uma ruptura necessária e fundamental, numa implicação político-social na transformação das relações societárias, convocando outras sensibilidades, que não aquelas supervalorizadas na razão tecnológica-científica predominante (ANDRADE, 2008, p. 71).

Neste sentido a Oficina de Criatividade vem romper com o modelo tradicional de se fazer psicologia, imprimindo um fazer menos autoritário, pois o trabalho se dá onde a

\footnotetext{
${ }^{2} \mathrm{Na}$ concepção de Andrade (2008, p. 55), moral é um sistema de julgamento externo e, como tal, incondicionado e absoluto, que relaciona sempre a existência a valores transcendentes. Aqui valores transcendentes nominam os valores que não estão dados na experiência, mas na moralidade e nas categorias estabelecidas de antemão, diferentemente do sentido de transcender como um ultrapassar-se a si mesmo, de uso mais frequente na tradição fenomenológica.
} 
vida do participante acontece e ele não é arrastado para o espaço psicológico, seu caráter é preventivo e/ou terapêutico e não tem restrição de público (CUPERTINO, 2008, p. 7-9).

Em um levantamento do histórico e trajetória da psicologia enquanto ciência e profissão (BOCK, 2003, p. 16), foi observado que por vezes esta ciência manteve um compromisso com as elites, numa prática voltada para o controle, a categorização e a diferenciação, nos quais o sujeito é responsabilizado pela vida que pode ter, o que valida a lógica neoliberal e reduz o sujeito. Esta psicologia torna-se de difícil acesso para os usuários de baixo poder aquisitivo, o que revela uma face de profissão de baixa inserção e compromisso social.

Guiamo-nos a partir de duas perspectivas críticas da psicologia tradicional, de Cupertino (2008) e de Bock (2003), para construir nossa intervenção. Procuramos fazer da Oficina de Criatividade uma abertura dos serviços psicológicos para um público historicamente negligenciado pelas modalidades tradicionais de atendimento, distanciando-nos da patologização dos comportamentos desviantes da norma moralmente estabelecida.

Nossa expectativa foi a de romper com o padrão de relacionamento estabelecido com o mundo e com as entidades assistenciais. Além de serem "saciadas" as necessidades materiais do público atendido, oferecemos-lhe o acolhimento de suas demandas emocionais, numa ruptura, ainda, com os modelos de patologização dos comportamentos, pensamentos e modos de viver. Isto através da proposta de aproximação e reconhecimento de seu modo de vida tal qual uma alternativa do viver e não apenas um desvio da norma. Em suma, nosso trabalho foi o de criar um espaço de ressignificação para um grupo comumente à margem das possibilidades de escuta psicológica (na prática mais elitista), e assim facilitar e favorecer o contato e abertura para outras possibilidades de ser e estar no mundo.

Para atingir tal objetivo empregamos uma postura fenomenológica, em que nos posicionamos como parte integrante do campo pesquisado. Em que o pesquisador está incluso neste movimento e ao mesmo tempo se deixa ver também, e se percebe de modo diferenciado, desvelando aspectos antes obscuros (LILIENTHAL; MORATO, 2008, p. 95-96). Neste trabalho afetamos e fomos afetadas e, para tanto, foi de suma importância nossa abertura para o contato com a experiência e com a criação de sentidos.

\section{Nosso fazer e a população do albergue}

Situada a postura empregada com a demanda que as Oficinas de Criatividade buscam favorecer, apresentamos o presente trabalho de relato de nossa experiência. Nossa intervenção se deu em um albergue, localizado na cidade de Sorocaba; a população foi composta em sua maioria por trecheiros, também conhecidos como andarilhos e migrantes, em uma população não homogênea. $\mathrm{O}$ que possuem em comum é o trecho, a estrada, um espaço em trânsito, deslocam-se constantemente, sem residência fixa ou trabalho regular (JUSTO; NASCIMENTO, 2005, p. 178).

Fractal, Rev. Psicol., v. 31 - n. 2, p. 91-101, 2019
A maioria dos participantes era do sexo masculino, havia drogradictos em recuperação, alguns egressos do sistema prisional, que se encontravam na condição de nomadismo por opção de vida, por escassez de possibilidades ou momentaneamente.

Há diversos acontecimentos que tornam o sedentarismo insuportável para esse público, propulsionando, por vezes, esses sujeitos a buscarem na estrada uma alternativa para amenizar o sofrimento. Questões como êxodo rural, baixa escolaridade, desqualificação da esfera profissional, uso abusivo de álcool e drogas, conflitos familiares, desemprego, desamparo, dentre outros, estão presentes na história de vida dos trecheiros (JUSTO; NASCIMENTO, 2005, p. 177-178).

Deste modo, a vida no nomadismo se distingue em muito do sedentarismo, a repetição é quase que inexistente na vida do trecheiro, as pequenas atividades cotidianas, como refeições, cuidados com a higiene pessoal, pernoite, se dão em diferentes condições das do dia anterior, exige-se continuamente uma atitude inovadora, revelando surpresas e descobertas. A trajetória é solitária e individual, o que torna o esforço pela sobrevivência ainda mais dificultoso; trata-se de uma condição de isolamento e escassez de relacionamentos pessoais (JUSTO; NASCIMENTO, 2005, p. 178).

Deste modo, o trabalho com trecheiros deve ter como norteador a concepção de que o nomadismo é uma alternativa de vida, sendo que os juízos de valor sobre o sedentarismo e as tentativas de direcionar o sujeito para este polo devem ser desconstruídas (JUSTO, 2005, p. 244-245), isto porque, ao deixar de migrar, o trecheiro também vive um choque, perda de identidade e despersonalização (JUSTO; NASCIMENTO, 2005, p. 186).

A partir deste referencial, o presente trabalho objetivou proporcionar um espaço de contato e experimentação de vivências diversas das deterministas no pensar e agir, direcionadas para a desconstrução da moral socialmente estabelecida e então voltada para uma apropriação das experiências individuais e coletivas.

As atividades propostas tinham o intento de proporcionar aos membros do grupo um ambiente acolhedor, no qual, se estivessem dispostos, poderiam ressignificar episódios de suas histórias de vida, repensar os modos como estabeleciam suas relações e refletir sobre como a normatização das relações tem papel determinante nos modos de pensar, sentir e agir.

Tomamos como referência para a realização deste trabalho as contribuições de Justo, que realizou intervenções junto de trecheiros e andarilhos. Delineamos algumas considerações e posicionamentos necessários para a realização do trabalho no albergue, dentre os quais destacamos: entrar em contato com a realidade deste público, não utilizando de nossa visão de mundo para julgar a realidade do outro, mas permitindo que o outro se mostre genuinamente; entender o nomadismo como uma alternativa de vida, abdicando dos juízos de valor sobre o sedentarismo ou nomadismo e tentativas de direcionar os sujeitos para um destes pólos; criar um espaço para que o usuário possa 
pensar sobre si, sem se sentir constrangido, cobrado ou censurado pelo seu estilo de vida; estabelecer um clima de respeito e valorização do sujeito; conhecer a cultura deste grupo e fortalecê-la; priorizar atividades em grupos e produções coletivas; e entender a expressão "morador de rua", ${ }^{3}$ enquanto a possibilidade de uma habitação ou a ausência de uma casa efetiva (JUSTO, 2005, p. 243-249).

As atividades ocorreram no espaço do pátio da instituição; os encontros tiveram frequência semanal, com grupos abertos, realizados no período entre 17 de setembro de 2012 e 05 de novembro de 2012, num somatório de oito encontros. Colocamos ainda à disposição dos participantes um caderno de registro das experiências, para que ali escrevessem o que desejassem, como meio, também, de compartilharem suas vivências com os demais usuários, tendo em vista a rotatividade existente no albergue.

\section{Encontros e desencontros}

A organização das propostas e temas das oficinas se deram inicialmente com um plano de atividades proposto ao espaço socioassistencial, mais no intuito de delinear os objetivos do que de engessá-los. Então a partir de cada encontro que ocorria captávamos alguma demanda emergente no grupo, com vistas ao encontro da próxima semana e assim sucessivamente. Aí elaborávamos uma proposta disparadora e dispúnhamos os recursos expressivos disponíveis que poderiam auxiliar neste processo. É importante investigar de quem é a necessidade que está sendo provocada na atividade, se do oficineiro ou do grupo; deve ser levado em conta o clima do grupo, o que se está para se desvelar na organização da proposta, pois todas as atividades são norteadas por um pedido e um tema para apoiar a produção (CUPERTINO, 2008, p. 11).

Ocorreu que, por vezes, devido ao tema que captávamos na semana anterior, organizávamos uma oficina com determinado propósito, mas, após esta se iniciar, o rumo que se seguia se desviava da nossa intenção inicial. Isto, em alguns momentos, causou-nos a impressão de que não estávamos realizando o objetivo proposto; todavia, posteriormente, refletindo sobre a experiência, pudemos compreender que foi este formato, de acolhida do emergente, que de fato possibilitou a expressão do que estava sendo trazido pelo grupo, atendendo a necessidade deste, e não a nossa, de fazer um trabalho dentro dos nossos moldes. Os participantes assumiram o papel de coordenadores, cabia a eles dar sentido àquela experiência e a sua produção. Assim como os trecheiros, nós tivemos de lidar com uma realidade em trânsito, nos surpreendendo a cada encontro, sendo inovadoras para nós mesmas, pois nenhum encontro era igual ao anterior, os participantes eram outros, assim como o clima grupal.

\footnotetext{
Com Brasil (2012) aprendemos que, no limite, ninguém "mora na rua", no máximo abrigam-se transitoriamente em instituições da Assistência Social, em calçadas, embaixo de marquises, dentre outros, ainda que com certa regularidade no tempo e no espaço. Assim, embora nos saberes que se apresentam como "de direito" os "moradores de rua" sejam 'pessoas físicas' unitárias, conforme passam a ter as suas subjetividades marcadas por arestas de inserção social adquirem outras referências, tais como: a pessoal na família, a noção de cidadania e numeração documental em referências de Estado, a cisão típica de processos inconscientes-conscientes nas abordagens que jogam com a noção de eu, de sujeito, de crise da interioridade e dessubjetivação, etc.
}

Após esta sensação inicial, notamos que, através dos recursos, o grupo vinculou-se a nós, com liberdade para colocar o que era de seu desejo naquele momento. Aspecto que tornou nossa prática diferente das propostas de atendimento tradicionais, em que o que é estabelecido pelo profissional, que detêm o conhecimento, é o que deve ser colocado em prática, muitas vezes desvalorizando o conhecimento do atendido.

Devido ao choque de expectativas, as oficinas se revelaram enquanto momentos de encontros e desencontros. À medida que o desenrolar das oficinas aparentemente se distanciava do objetivo que havíamos proposto para o encontro, se aproximava do objetivo da prática como um todo, da livre expressão do conteúdo que pedia passagem, da vinculação, da valorização e fortalecimento da cultura e história de vida dos participantes, numa abertura para outras possibilidades do fazer psicológico, pensar, sentir e ser, tanto para os participantes quanto para nós, oficineiras, afinal também estávamos inseridas no grupo, afetando e sendo afetadas por ele.

Abaixo segue um breve relato de cada encontro, para ilustrar as colocações acima:

Primeiro encontro - Para o primeiro encontro, planejamos uma oficina de autorretrato, com o intuito de conhecer um pouco dos participantes, de suas histórias, e favorecer um momento em que eles pudessem entrar em contato consigo mesmos. Foram disponibilizadas folhas de sulfite, lápis grafite e de cor.

$\mathrm{Na}$ execução da proposta os participantes apresentaram uma perspectiva diferente de autorretrato da que havíamos proposto; ao invés de se desenharem, começaram a representar no papel os lugares por onde passaram durante suas trajetórias. Foi a partir de então que começaram a compartilhar conosco suas histórias e experiências de vida, de modo que conduziram a oficina. Houve ainda, por parte dos integrantes, um movimento para nos aproximar deles. Eles próprios nos despojaram do nosso lugar de suposto saber psicológico, de relação hierarquizada, nos chamaram a sentar todos juntos no chão e, partir deste momento, as relações se horizontalizaram, não ocupávamos um lugar diferente, passamos a compor um grupo.

Entendemos que a nossa concepção de autorretrato se diferenciava por priorizar a imagem corporal, a condição de estar em determinado momento com uma aparência ou outra; em contrapartida, os participantes trouxeram o ser, as imagens que compõem seu modo de vida, o que faz parte de sua subjetividade, numa perspectiva mais ampla, as histórias, lugares, memórias, tudo isto compunha a imagem de si mesmos. A imagem de si mesmos "deles" incluía as paisagens onde estiveram e não podia ser resumida num retrato.

Segundo encontro - A partir do encontro anterior, trazido o conteúdo do espaço em trânsito, propusemos utilizar a música "Saudosa Maloca" para a realização de uma produção em grupo sobre o que a música suscitaria nos participantes, objetivando dar voz aos diversos tipos 
de morada possíveis, experiências e vivências relacionadas ao tema. Utilizamos como recursos a música, papel pardo, giz de cera, cola colorida e lápis grafite.

A escolha da música pareceu mobilizar muito os participantes, que, de início, permaneceram silenciosos. Levou algum tempo até que iniciássemos um diálogo; antes de isto acontecer, eles evocaram outros estilos musicais, através dos quais puderam comunicar o que estavam pensando e sentindo naquele momento. A oficina não se deu do modo como havíamos planejado, predominaram as produções individuais, assim como os relatos não compartilhados e integrados com o grupo. Emergiram questões da destruição e reconstrução da "saudosa maloca", fatos que ocasionaram o nomadismo e as expectativas em relação ao futuro. A condição de trecheiro, de acordo com os relatos, foi precedida por conflitos familiares, principalmente envolvendo uma figura feminina, esposa, mãe, filha, etc. A crença religiosa foi bastante presente e compartilhada na vida de alguns participantes; junto ao discurso religioso foi comum haver falas de esperanças na modificação da realidade.

A escolha da música "Saudosa Maloca” paralisou o grupo, a letra trata de uma morada fixa que se perdeu e acabou por suscitar memórias de perdas e sofrimento. A nossa expectativa era a de que pudessem compartilhar essas experiências e ressignificá-las numa troca coletiva; no entanto, negligenciamos o fato de que os trecheiros vivem em condição de isolamento e rarefação das relações sociais, sendo o nomadismo, por vezes, uma resposta a situações insustentáveis, sejam de relações familiares, de questões financeiras, de saúde, etc. Não seria possível, portanto, que no início de um trabalho alcançássemos o nosso objetivo.

No entanto, na roda do grupo, ainda que em conversas mais particulares, os participantes puderam trazer os conteúdos referentes ao período em que se tornou insustentável o sedentarismo. Vislumbraram perspectivas de vida como retornar à casa da família, conseguir um emprego fixo, ou permanecer vivendo de trecho em trecho. Foi neste encontro que pudemos compreender, na prática, do que se tratava ser um trecheiro, e isso foi novo para nós.

Terceiro encontro - Atentamos no encontro anterior para a relação dos participantes com seus corpos e com o espaço da instituição. Por vezes eles se queixavam de cansaço, dores no corpo, sono, desejando uma cama para descansar, pois o dia havia sido exaustivo. Na instituição recebiam a refeição e o leito para o pernoite, ambos com horário determinado. Para lazer contavam com uma televisão numa área comum e algumas revistas. Não podiam circular livremente pelo espaço físico, um vigia permanecia atento aos comportamentos do grupo.

Diante desta situação, a vida em trânsito, suas repercussões no corpo e a restrição de circulação na instituição, organizamos uma oficina com o propósito de propiciar aos participantes um maior contato com seus corpos, escutar, perceber o que o corpo solicita e atendê-lo, da maneira que fosse possível. Pensamos em trazer as histórias de vida através do corpo, sua imagem e a relação do participante com sua corporeidade, as marcas, os pés com fissuras, as tatuagens, as cicatrizes, a envergadura de postura - o corpo tinha muito a comunicar sobre os trajetos de cada participante.

Organizamos a oficina deste dia em três momentos: primeiro com uma atividade de relaxamento e automassagem, para que os participantes pudessem se apropriar de seus corpos, entrar em contato consigo mesmos. Em seguida fizemos um exercício de ocupação do espaço, caminhando e explorando o local da oficina, momento em que se incentivou o contato visual e a formação de grupos, com a intenção de promover a vivência de outras possibilidades de se relacionar com o espaço e com os demais participantes. Para encerrar, estimulamos a construção de caminhos, com papel pardo pelo chão, onde cada integrante poderia construir ou representar momentos de sua vida, assim poderiam compartilhar suas trajetórias e experiências de vida no trecho. Para tanto foram disponibilizados papel pardo e giz de cera.

As atividades de relaxamento e automassagem pareceram provocar desconforto nos participantes devido à proposta de entrarem em contato com o próprio corpo, habitualmente não se tocavam, e a vida no trecho exige estado de alerta, não podendo relaxar. Contudo, percebemos o surgimento da tensão e, atentas ao clima do grupo, viabilizamos a possibilidade de um grito coletivo, com a intenção de dar vazão aos conteúdos que até então não puderam ser verbalizados, o que se mostrou uma oportunidade de vazão e alívio aos participantes, principalmente pela distância dos moldes institucionais. Começamos então a demarcar o espaço da Oficina de Criatividade como um espaço divergente do padrão de funcionamento da instituição.

$\mathrm{Na}$ segunda etapa da oficina, quando propusemos a ocupação e exploração do espaço, alguns participantes se sentiram desconfortáveis, abandonando a atividade no momento em que se sugeriu a formação de duplas, seguidas por trios e grupos. Notamos aqui a nossa idealização de planejamento, ao pressupor que seria fácil para os participantes se aglomerarem em grupos para caminharem juntos - o que para nós era habitual, na rotina de trecheiro é exceção, a trajetória é solitária, os participantes que abandonaram esta etapa da oficina tinham ingressado havia pouco tempo no albergue e havíamos nos conhecido neste encontro. Dado o molde institucional do albergue o grupo era necessariamente aberto. No entanto, alguns participantes, que se vincularam anteriormente com o formato da oficina, sentiram-se satisfeitos com a integração grupal; com estes nós já vínhamos caminhando juntos, havia um vínculo anterior que permitiu essa proximidade.

$\mathrm{Na}$ etapa de construção de caminhos, para representar as trajetórias, a prática se distinguiu da ideia que havíamos planejado, imaginamos uma construção individual compartilhada com o grupo. Os participantes se reuniram, espontaneamente, em duplas ou trios e compartilharam trechos de suas histórias, falaram dos lugares por onde passaram, das características da população de cada região e dos aprendizados que tiveram. Entendemos que foi o processo como um todo que possibilitou esses encontros de pequenos grupos, os temas compartilhados 
se referiam a passagens por penitenciárias e internações para desintoxicação, foi ficando mais claro para nós e para eles o quão tinham em comum.

Uma das possibilidades da Oficina de Criatividade é a formação de uma rede de suporte e sustentação, através da troca de experiências e vivências (CUPERTINO, 2008, p. 9). Em um dos encontros isto se expressou, dois participantes desenvolveram uma amizade, que se desdobrou para além do espaço da oficina e do albergue. Eles saíram juntos à procura de empregos e posteriormente alugaram uma casa, ambos tinham idades e vivências diferentes e ressaltaram o quanto um conseguiu e poderia aprender com o outro.

Quarto encontro - Captando o modo de relação com a instituição, os papéis desempenhados nas relações, e pensando sobre as posturas rígidas e automatizadas reproduzidas para atender às normas socialmente aceitas e instituídas, propusemos uma oficina que trabalhasse as posturas assumidas. Organizamos duas etapas; na primeira utilizamos uma música, durante a qual os participantes iam caminhando pelo espaço e, quando ouvissem uma palma, deveriam fazer alguma posição próximos ao chão; duas palmas, uma posição numa estatura média; três palmas, uma posição no alto. Na segunda etapa, utilizando papel sulfite, lápis grafite e de cor, sugerimos uma reflexão sobre o momento em que se percebiam em cada uma das três posturas e, em seguida, pedimos que representassem isto no papel.

Tanto na atividade corporal quanto na gráfica, notamos que houve mais reproduções do que produções, de modo que passaram a imitar as posições já realizadas pelas estagiárias e a desenhar objetos concretos, sem que realizassem uma reflexão acerca das posturas cotidianas reproduzidas automaticamente, como se estivessem apenas realizando o que solicitamos, sem que aquilo tivesse suscitado algum sentido para o grupo.

Em contrapartida, o grupo passou a direcionar o tema para a relação com as figuras femininas de suas vidas, dentre elas nós, as estagiárias ${ }^{4}$ no aqui-e-agora com eles. A nossa presença, três mulheres, uma loira, uma negra e uma parda, num ambiente em que a grande maioria dos participantes era do sexo masculino, trouxe à tona a questão da relação com o feminino, foi esta relação conosco o recurso utilizado neste encontro. A escuta, o vínculo e os afetos proporcionaram o resgate da memória de relações anteriores, algumas rompidas, outras distantes, ou em processo de reaproximação. Resgataram como eram vistos e como viam estas figuras, suas experiências e afetos, e reavaliaram os papéis que desempenharam na qualidade de pais, filhos, esposos, irmãos, namorados, amantes, etc.

Nas oficinas de criatividade o tema deve ser apresentado de forma vaga, de modo que possa acolher o que o participante entenda da proposta (CUPERTINO, 2008, p. 5). A partir deste referencial compreendemos que quando os participantes se colocaram de maneira mais próxima de nós puderam também resgatar e lançar o olhar sobre o

\footnotetext{
${ }^{4} \mathrm{O}$ grupo de estagiárias era composto por três estudantes do sexo feminino.
}

modo como se relacionam ou se relacionaram com as figuras femininas de suas vidas e como elas se relacionam ou se relacionaram com eles.

Pudemos perceber o quanto nossa presença trazia algo de diferente para a vida desses trecheiros; por vezes eles relatavam não se sentirem vistos pelas pessoas nas ruas. Era como se não existissem. $\mathrm{O}$ nosso interesse em estar junto deles foi fator que gerou surpresa, se sentiram valorizados, escutamos falas como "vocês poderiam estar em casa agora, mas escolheram estar aqui com a gente". Essa percepção já apontava uma reavaliação de si mesmos, agora como sujeitos de valor.

Quinto encontro - Percebendo ser o movimento do grupo mais produtivo quando valorizada a experiência e a sensação, cogitamos uma oficina com argila, procurando valorizar a exploração dos sentidos e da maleabilidade e a diversidade de construções que este recurso possibilita. Solicitamos que os participantes explorassem o material e fizessem com ele algo, o que desejassem, uma produção livre.

A argila é um material impreciso, contudo isso não constituiu um fator de dificuldades para os participantes, eles se sentiram à vontade com o material, perceberam-se capazes de produzir algo, valorizando-se e reconhecendo nos demais esta capacidade.

Um participante tinha atritos com uma irmã, fez um animal desengonçado e apresentou-nos como sendo sua irmã, foi crítico com ela, queixou-se de seus comportamentos com ele, mas ao longo do encontro foi cuidadoso com sua produção. Em dado momento mencionou que estava ficando frio e cobriu sua peça, a irmã, com um pano, para protegê-la do vento.

Em cada encontro um participante se destacava por alguma habilidade específica, como desenho, composição musical, poesia, habilidades manuais, com charadas e raciocínio lógico. Estes aspectos eram valorizados no grupo, tanto pelas estagiárias quanto pelos participantes, o que fazia se sentirem reconhecidos por algo, valorizados e singulares. Assinalaram o quanto este era um aspecto oposto ao vivenciado em outros serviços, em que eram atendidas apenas suas necessidades materiais e sofriam discriminação devido à condição de nomadismo.

Sexto encontro - A partir dos conteúdos emergentes no encontro anterior, propusemos uma oficina com o intuito de que os participantes resgatassem aquilo que consideram importante para si mesmos, e quais aspectos entendiam ser representantes das relações humanas; usamos como recurso uma história. O relato foi "um extraterrestre vem conhecer o nosso planeta, ele deseja conhecer aspectos da vida e hábitos dos seres humanos". A partir deste disparador solicitamos que os participantes, utilizando revistas, tesoura e cola, destacassem aquilo que consideravam importante este visitante conhecer.

Houve uma dificuldade devido ao material disponibilizado, pois os conteúdos das revistas, em sua maioria, expressavam aquilo que é socialmente reconhecido 
e mercadologicamente incentivado e vendido como necessidades a serem supridas. Contudo isto não pareceu interferir, maciçamente, na produção grupal.

Emergiu a questão da necessidade de escuta, esta foi amparada pelo acolhimento das vivências de cada participante expressas no e pelo grupo, por vezes ligadas à vida de trecheiro, uso e abuso de drogas e privação de liberdade. Resgataram suas historicidades e deram voz ao sofrimento que por vezes é inaudível devido a juízos de valor.

Posteriormente, refletindo sobre esse encontro, nos demos conta da simbologia da história - nós éramos como os extraterrestres da história desejando conhecer um pouco mais sobre esta população, e eles vieram ter conosco, nos apresentar seu mundo, sua cultura, linguagem, relacionamentos, por vezes distintos da realidade que cada uma das estagiárias vivenciava em seu cotidiano.

Sendo assim, embora as produções materiais não expressassem esses conteúdos, a fala colocada em circulação no grupo pôde dar conta do objetivo do encontro, trazer as histórias e trajetórias de cada participante, desta vez compartilhadas em grupo, atentando para as semelhanças dos conteúdos. Cada um pôde trazer um pouco do que era importante para si, suas relações e olhar para tudo isto, e perceber o olhar do outro, este que se encontra do lado de fora, as extraterrestres estagiárias, ausente de reprovação, desvalorização e discriminação.

Sétimo encontro - Tendo em vista o grupo ter se aberto para as expressões no coletivo e a nossa aspiração de que o espaço da oficina fosse instrumento de vazão daquilo que é sentido e vivido como inaudível e incomunicável, organizamos um encontro em que foi sugerida a realização de um programa de televisão. Coube aos participantes dar nome ao programa e escolher os entrevistados e temas das entrevistas; puderam fazer perguntas para as estagiárias, houve momento cultural e um espaço para falarem abertamente sobre o que desejassem.

A construção do programa de televisão surpreendeu os participantes e eles se envolveram com a proposta. Montamos no pátio uma espécie de auditório e um púlpito, levamos câmera para filmar, caixa de som e microfone.

Após as organizações e acertos iniciais começamos o programa. O tema das entrevistas foi "A vida de trecheiro", os participantes contaram um pouco de suas trajetórias, das vivências no trecho e diferenciaram o trecheiro (pessoa nômade que leva a vida trabalhando de trecho em trecho) do pardal (aquele que não tem morada fixa, mas se estabelece em uma região, bairro ou cidade) e do encharcador (a pessoa nômade que ganha a vida aplicando golpes e pedindo dinheiro). Todos os participantes enfatizaram a importância de serem diferenciados os tipos chamados de nômades.

Outros participantes destacaram as dificuldades enfrentadas no trecho "A estrada é um tapete preto, ali é o maior aprendiz, o qual ensina a enfrentar as coisas" (sic), desde os olhares e dizeres discriminatórios recebidos nas ruas, passando pela repressão policial e intervenções moralistas de profissionais e instituições de suporte social. Posicionaram-se criticamente em relação às intervenções profissionais e de instituições, destacaram que necessitam destes serviços de acolhimento; contudo, por vezes, eles se convertem em fatores de exclusão e marginalização social.

Houve intervalos entre as entrevistas para momentos culturais em que alguns participantes se voluntariaram para cantar. O ritmo predominante foi o samba, dentre eles o "Deixa a vida me levar... vida leva eu", de Zeca Pagodinho, entoado em coro, alguns até se colocaram a dançar, a plateia foi incentivadora e participativa.

A oficina foi encerrada com um momento de fala livre, em que os participantes puderam usar o microfone para dizer o que tivessem vontade "para o mundo". Dentre as falas houve elogios à instituição; críticas aos serviços de suporte social e ao descaso do Estado com esta população pelo modo como são recebidos e tratados, faltando aceitação do nomadismo como possibilidade de vida e políticas que compreendam esta perspectiva, pois, por vezes, as instituições dificultam o trânsito livre dos trecheiros e tendem a conduzi-los ao sedentarismo. Falaram também sobre família, emprego, saúde, educação e agradeceram a intervenção realizada neste encontro e o espaço proporcionado; acentuaram não terem vivenciado nada similar em outras instituições de acolhimento.

Este foi o primeiro encontro em que o que foi planejado se aproximou do que se realizou. Houve trocas no grupo, com ampla participação dos presentes e liberdade de expressão, seja ela verbal ou corporal. Entendemos ser este um resultado de um processo construído ao longo dos encontros anteriores, que nos tornou mais sensíveis à demanda e formas de facilitar a expressão grupal.

Um elemento significativo, e que representou uma ressignificação do espaço institucional, foi que um dos participantes, que esteve conosco desde os primeiros encontros e posteriormente deixou de usar o serviço do albergue, compareceu à instituição em todos os dias dos encontros da Oficina de Criatividade, passou a ser um facilitador de nosso trabalho, articulava junto aos demais participantes, apresentava a proposta de trabalho e ajudava a integrar aqueles que ainda não conheciam a oficina ou a instituição, e no encontro do programa de televisão ele foi um dos organizadores, apropriou-se da proposta de intervenção.

Oitavo encontro - Para a última oficina pensamos em uma atividade de produção criativa, em que se valorizasse a produção individual e se estimulasse a troca entre os participantes, e ao mesmo tempo fosse um agradecimento pela participação e abertura ao trabalho da Oficina de Criatividade. Sendo assim, tendo em vista que a oficina acontecia após o período do jantar e que por vezes havia comentários de faltar um "docinho", propomos uma atividade de culinária - como recursos disponibilizamos chantilly, morangos e abacaxis picados e suspiros, para a confecção de merengues.

Todas as oficinas aconteceram no pátio de estacionamento da instituição, nos sentávamos no chão, numa área aberta em que era possível ver o céu, havia diversas árvores no espaço. Neste encontro, tendo em vista a especificidade da atividade, realizamos a oficina no refeitório da instituição, um espaço amplo, com mesas e bancos. 
Apresentamos os ingredientes que levamos e explicamos que poderiam confeccionar seus merengues da forma que desejassem. Alguns dos participantes nunca haviam experimentado o chantilly, cada um a sua maneira compôs seu doce, alguns usaram todos os ingredientes, outros preferiram apenas cada um isoladamente, só as frutas, o suspiro ou o chantilly. Ficaram muito empolgados com a atividade, alguns participantes confeccionaram os doces e trocaram com colegas ou estagiárias, mas a maioria fez sua produção e a consumiu.

Durante a preparação e degustação, o diálogo teve conteúdo de agradecimento, pontuaram como aquele alimento foi reconfortante. Um usuário comentou que fazia anos que não recebia uma demonstração de afeto, há dez anos não recebia um beijo no rosto, e naquele momento o merengue era tão afetuoso quanto o beijo. Logo em seguida, outro usuário, que jantava do outro lado do refeitório e ouviu o relato, veio na direção do primeiro e lhe deu um beijo no rosto.

Neste dia a maioria dos participantes não era de trecheiros, mas sim de pessoas que passavam por um momento de dificuldade e necessitaram recorrer ao abrigo. Em suas falas trouxeram diversas críticas ao modo como são recebidos pelas instituições de acolhimentos, destacando que, por diversas vezes, foram tratados com falta de respeito, sendo desapropriados de seus direitos e sofrendo inúmeros preconceitos. Ressaltaram entender que existem interesses econômicos nestas instituições e que por vezes o serviço não se dá de acordo com as propostas; deste modo, não se sentem assistidos e considerados como cidadãos que compõem a sociedade.

Informamos que este era o nosso último encontro, houve diversas falas de que este tipo de intervenção deveria ser incentivado e se diferenciava dos atendimentos psicológicos tradicionais pelos quais passaram.

Neste encontro observamos dois propósitos do trabalho que vieram se delineando ao longo do processo. Um deles foram as atividades grupais; no início era muito difícil que as trocas ocorressem, mas, com o passar do tempo, elas se tornaram mais frequentes e ricas, possibilitando até trocas afetivas, como o beijo neste encontro, as amizades em outros e a confiança de poder compartilhar a história, o momento, o merengue, etc. Outro aspecto observado foi a possibilidade de os moradores de rua que participaram das oficinas ressignificarem o trabalho do psicólogo e das instituições, pois no lugar de categorias e patologizações psíquicas puderam encontrar confiança no acolhimento e aceitação do modo de vida que lhes é próprio.

\section{O processo de produção grupal}

O usuário deve ser escutado sem que haja um viés preconceituoso, de censura, cobrança ou desabono do estilo de vida, mas, ao contrário, de valorização e respeito pelo sujeito (JUSTO, 2005, p. 244-246). Foi este o clima que procuramos produzir na oficina e que os próprios participantes acabaram por desenvolver, apropriando-se da proposta de trabalho.
Neste mesmo sentido, as intervenções psicológicas devem conduzir o participante à pulsação, sem que a realidade seja nomeada, de modo que tal postura gere um endurecimento das possibilidades (PESSANHA, 2000, p. 108-109;119). A história de cada um deve ser valorizada, pois se constitui enquanto a raiz do ser. Deve ser favorecida a proximidade entre as possibilidades existentes e não vivenciadas e aquelas vivenciadas, de modo a facultar a probabilidade de encontrar o outro, puxando o recluso e permitindo a manifestação de tudo o que se é.

No entanto, o que percebemos, por meio do relato dos integrantes do grupo, é que as instituições que atendem esse público costumam compreender que reintegração social implica sedentarismo, com trabalho e residência fixa, assim como o restabelecimento dos laços familiares, elemento confirmado por alguns autores (JUSTO, 2005, p. 244-245). Estes elementos idealizados de vida reintegrada como vida sedentária nós percebemos no discurso do serviço de assistência social, enraizado de tal modo que também se fez presente, durante os nossos encontros, na fala dos próprios usuários.

Consideramos que embora possa ser desejável que o trecheiro tenha a possibilidade de se sedentarizar, esta não deve ser objetivada como a única saída para a reintegração social, uma vez que a vida de trecheiro precisa de amparo do Estado tal como ela é, com sua movimentação característica pelos espaços. E isto pede por serviços socioassistenciais com esta abertura e uma abordagem psicológica que não constranja o trecheiro a uma vida sedentária indesejada.

A psicologia esteve comprometida com os interesses das elites, numa perspectiva de fortalecer o movimento higienista, diferenciando e categorizando; compreendia o desenvolvimento psíquico como resultante da natureza humana e não exigia um posicionamento crítico, o que acabou afastando os psicólogos das preocupações sociais (BOCK, 2003, p. 18-20).

O que observamos em campo é que os trabalhos oferecidos à população de rua, de acordo com os discursos dos participantes, seguem esta ótica, de haver um padrão, uma maneira de ser socialmente aceita, e que aqueles que se desviam desta norma são rotulados de perfis patológicos. No entanto, ao se depararem com um serviço de psicologia que não procurava "entrar em suas mentes" (sic), puderam vislumbrar outras possibilidades de se relacionarem com os profissionais e consigo mesmos.

Outro elemento que foi vinculado durante o trabalho foi a cultura dos trecheiros; os participantes nos apresentaram o modo como vivem, sua linguagem, seus ditados, etc. Pontuavam como esses aspectos deveriam ser diferentes do nosso modo de vida, mas, quando entraram em contato com fatos que aproximavam as oficineiras do modo de ser do grupo, ficaram surpresos e lançaram um outro olhar para a relação conosco.

\footnotetext{
${ }^{5}$ Esta expressão foi usada diversas vezes pelos participantes após nos apresentarmos como estudantes de psicologia, isto nos remeteu ao modo como eles percebiam e sentiam a intervenção psicológica dos serviços aos quais foram submetidos, esta era sentida como invasiva.
} 
Certa vez uma das estagiárias foi vista nas proximidades da rodoviária com algumas mochilas - é na rodoviária que o veículo do albergue busca os trecheiros para passarem a noite no albergue, e é comum que estes tenham consigo mochilas e pertences. Na semana seguinte a este ocorrido, um participante que tinha visto a estagiária brincou com a situação, perguntando se ela havia perdido a carona para a instituição. A partir deste fato, que se deu fora do espaço das oficinas, os participantes perceberam aspectos que tinham em comum com a vida das estagiárias, o que favoreceu a relação de horizontalidade que estabeleceram durante os encontros.

Nas oficinas podem ocorrer importantes transformações em curtos períodos de tempo, sendo que, por vezes, o que a pessoa precisa é de um espaço onde seja escutada e onde possa trocar experiências com outros membros do grupo (CUPERTINO, 2008, p. 9). Ou seja, as trocas são um elemento muito importante, na medida em que ampliam a experiência de todos. As conversas são postas na roda, para que possam circular, de forma que os participantes possam dar andamento àquelas demandas, sozinhos ou coletivamente. Ao psicólogo cabe apenas facilitar esse trânsito.

Neste sentido, os recursos expressivos e a nossa própria presença, na qualidade de instrumento de trabalho, facilitaram a vinculação de temas pelo grupo, para que revisitassem aspectos de suas histórias e reconhecessem suas potencialidades. Quando escutados, puderam colocar-se criticamente em relação ao modo como são (pré)concebidos, atendidos e tratados socialmente, isto tanto pelas pessoas na rua quanto pelos funcionários nos serviços que utilizam.

Deste modo, nosso trabalho na Oficina de Criatividade, desenvolvido neste contexto, pode se distanciar do molde tradicional de atendimento psicológico, que tende a categorizar e patologizar comportamentos; as relações foram horizontalizadas, não havia um saber predominante. Os participantes, ao longo do processo, puderam se apropriar da proposta, e passaram a coordená-la. Foi a partir dos conteúdos emergentes do grupo que procuramos trabalhar suas histórias e sentidos, apenas colocando-as em trânsito. Esses encontros constituíram um espaço de troca; ao mesmo tempo em que nós possibilitávamos um espaço e uma relação diferenciada, eles também nos ensinavam sobre aspectos da vivência de trecheiro, sobre lugares em que passaram, conhecimentos que agregaram, seus ditados, forma de linguagem, foi um universo que se abriu para nós.

Essas foram algumas das vivências que puderam ser compartilhadas entre os trecheiros durante a atividade, ou seja, resgatar aspectos deste estilo de vida, entendendo-os enquanto resultados de uma construção social, sem culpabilizar ou realizar qualquer julgamento sobre os sujeitos, mas vinculando-os aos seus discursos, experiências, vivências e saberes.

\section{Considerações finais}

A Oficina de Criatividade tem um caráter de abertura e (des)construção contínua implicado no seu fazer. Sua proposta é a de promoção de uma aproximação do indivíduo, utilizando os meios de expressão artística, para que, através de suas experiências, vivências, sentimentos, pensamentos e relações, o participante possa conceber, caso deseje, perspectivas ampliadas, aumentando, assim, suas possibilidades de ser-no-mundo.

Este aspecto se torna extremamente necessário quando atentamos para as determinações sociais e morais no modo de ser de cada sujeito, sendo que muito de sua essência se perde nesta restrição e ocultamento. Esta modalidade de atendimento tem o propósito de resgatar o sujeito, sua integralidade, individualidade, história, características pessoais e o vínculo com o outro e com a realidade que o rodeia, entretanto com o intuito da apropriação e não o de reproduzir o que já está socialmente instituído.

Neste sentido, a prática do oficineiro não pode ser irrefletida, mas sim atenta a tudo que a cerca, pautada num constante questionamento, e sem negligenciar os sentimentos, pensamentos, intuições e clima estabelecido com o grupo, para que assim não se constitua em um instrumento de controle, mas sim um instrumento facilitador para o desvelamento, rompimento ou criação.

A partir dos encontros realizados, notamos que os participantes, nos diversos serviços nos quais foram atendidos, tiveram a atenção e o cuidado voltados para suas necessidades materiais, ao passo que o sofrimento psíquico era negligenciado. No entanto, notamos uma possibilidade de oxigenação de tais práticas, quando, no último encontro foi sugerido pelos agentes institucionais que realizássemos uma exposição dos materiais produzidos durante os encontros. Esta exposição foi realizada no início do ano seguinte, se deu no auditório da instituição concreta e contou com a presença dos usuários que se encontravam no local nesta data.

Notamos, assim, um reconhecimento tanto de nosso trabalho quanto de certos aspectos da singularidade da vida de trecheiro por parte do serviço socioassistencial. Este desdobramento de nossos encontros possibilitou valorizar as produções estéticas dos trecheiros e moradores de rua em geral e indicou que unir elementos artísticos com saberes psicológicos é uma alternativa de apoio para esta população.

A modalidade de Oficina de Criatividade se mostrou efetiva na medida em que possibilitou a ressignificação, a abertura para a alteridade e a construção em conjunto de significados, em que a relação não foi de hierarquia, mas sim de horizontalidade, com intensas trocas, experiências, vivências, nas quais o saber proveniente de diferentes referenciais foi posto na roda, com mútuas afetações.

A experiência com a realização das oficinas e as afetações foram registradas através da poesia que fizemos de maneira a sintetizar, apesar de não ser possível resumir em palavras, aquilo que vivenciamos junto aos participantes das oficinas:

\footnotetext{
"Trecheiro também é cultura"

Aprendi que...

Trecheiro é quem tem a casa em si mesmo.

Pardal não é necessariamente um pássaro.

Encharcador se aproveita das oportunidades.

Paca também é um inseto peludo.

Que às vezes fico firme que nem prego na areia

Outras deixo cavalo celado passar.

Que a casa de sapé tem teto de palha,

$E$ "sabê" é conhecer vivendo.
} 
Em campo, a partir da realização dos encontros no albergue, notamos que a demanda apresentada pela população-alvo circundava o tema da necessidade de um espaço para o diálogo sobre suas vivências e culturas. Os diversos participantes dessa população, chamada "população de rua", expressavam o anseio por um espaço em que pudessem refletir sobre seus aspectos vivenciais e culturais, podendo inclusive tomar um posicionamento crítico a respeito dos serviços socioassistenciais direcionados a eles.

Este cenário veio ao encontro da nossa proposta de intervenção, ou seja, vincular a cultura do trecheiro. Entendemos que cultura se refere às produções de um grupo social, seus valores, crenças, aspectos de seu cotidiano, e assim procuramos valorizar o saber que traziam consigo.

Outro aspecto que emergiu nas conversas foi o modo como eles são percebidos e tratados pela sociedade e pelas instituições de acolhimento. Os participantes revelaram o distanciamento que experimentam nestas relações, acentuaram que as instituições de apoio social, através das atitudes direcionadas aos usuários, reforçam a marginalização que sofrem, tendo como referência o sedentarismo, a norma socialmente aceita, culpabilizando-os e discriminando-os por suas "opções" de vida.

Neste sentido, criou-se uma abertura para que os integrantes do grupo pudessem vincular aspectos que não eram acolhidos pelo serviço socioassistencial, ou seja, uma abertura para outras perspectivas, modos de pensar, sentir e ser. Neste ambiente institucional, a imagem acerca dos trecheiros estava cristalizada, havia certa desvalorização dos conhecimentos e experiências próprias. A instituição os concebia como seres errantes, que não se enquadraram no modelo hegemonicamente aceito e reproduzido socialmente, tomando como medida o emprego e a moradia fixos e a formação de núcleos familiares harmoniosos. Neste contexto, entendemos que a Oficina de Criatividade poderia servir de fator oxigenador, permitindo a circulação de novos ares, numa abertura para percepções antes não contempladas.

\section{Informações sobre as autoras:}

Renata Santos Leme Ferreira

(iD) https://orcid.org/0000-0003-4398-6466

(9) http://lattes.cnpq.br/1276088017556831

Possui graduação em Psicologia pela Universidade Paulista (2013)

e Pós-graduação Lato Sensu em Gestão das Políticas Sociais pela Universidade Paulista (2015).

Simone Cristina de Amorim

(iD) https://orcid.org/0000-0002-0897-6484

(9) http://lattes.cnpq.br/0068826059223733

Graduada em Psicologia (Formação de Psicólogos, Bacharelado e Licenciatura), com Residência Multiprofissional em Atenção à Saúde, Mestrado em Filosofia e Título de Especialista na área de Psicologia em Saúde.

\section{Letícia Geraldo Firmino}

(iD) https://orcid.org/0000-0001-9840-8263

\section{(9) http://lattes.cnpq.br/2092283400722696}

Possui graduação em Psicologia pela Universidade Paulista (2012). Pós-graduação Lato Sensu em Psicodrama (Associação Brasileira de Psicodrama e Sociodrama - ABPS)

\section{Isabela Cristina Ortiz Gambaro \\ (iD) https://orcid.org/0000-0001-6591-2594 \\ (9) http://lattes.cnpq.br/7605691159294600 \\ Pós-graduação Lato Sensu em Acupuntura (Centro de Estudos de Terapias Naturais - CETN)}

\section{Contribuições das autoras:}

Renata Santos Leme Ferreira foi responsável pela coleta, concepção, desenho, interpretação dos dados, revisão e aprovação da versão final do artigo. Simone Cristina de Amorim: foi responsável pela concepção, desenho, análise, interpretação dos dados, revisão e aprovação da versão final do artigo. Letícia Geraldo Firmino foi responsável pela coleta, desenho, interpretação dos dados e aprovação final do artigo. Isabela Cristina Ortiz Gambaro: foi responsável pela coleta, desenho, interpretação dos dados e aprovação final do artigo.

\section{Como citar este artigo:}

\section{ABNT}

FERREIRA, Renata Santos et al. Oficinas de Criatividade: atendimento à população de rua. Fractal: Revista de Psicologia, Niterói, v. 31, n. 2, p. 91-101, maio/ago. 2019. https://doi. org/10.22409/1984-0292/v31i2/5620

\section{APA}

Ferreira, R. S., Amorim, S. C., Firmino, L. G., \& Gambaro, I. C. (2019). Oficinas de Criatividade: atendimento à população de rua. Fractal: Revista de Psicologia, 31(2), 91-101. doi:10.22409/19840292/v31i2/5620

\section{Referências}

ANDRADE, Ângela Nobre de. Oficinas de Criatividade: Deslocamentos e Com-Posições. In: CUPERTINO, Christina M. B. (Org). Espaços de criação em Psicologia: oficinas na prática. São Paulo: Annablume, 2008. p. 53-76.

BOCK, Ana Mercês Bahia (Org.). A Psicologia e sua ideologia: 40 anos de compromisso com as elites. In: compromisso social. São Paulo: Cortez, 2003. p. 15-28.

BRASIL. Ministério da Saúde. Secretaria de Atenção à Saúde. Departamento de Atenção Básica. Manual sobre o cuidado à saúde junto a população em situação de rua. Brasília: Ministério da Saúde, 2012. Disponível em: http://189.28.128.100/dab/ docs/publicacoes/geral/manual_cuidado_populalcao_rua.pdf. Acesso em: 09 jun. 2019.

CUPERTINO, Christina Menna Barreto. O cultivo da imaginação e a atenção à diversidade. In: SIMPÓSIO NACIONAL DE PRÁTICAS PSICOLÓGICAS EM INSTITUIÇÃO, 7., 2007, São Paulo. Anais... São Paulo: PUC/Liber, 2007. p. 1-12.

CUPERTINO, Christina Menna Barreto. Atuação em campo com Oficinas de Criatividade: que Psicologia se faz? In: SIMPÓSIO NACIONAL DE PRÁTICAS PSICOLÓGICAS EM INSTITUIÇÕES, 8., 2008, São Paulo. Anais... São Paulo, 2008.

JAPIASSÚ, Hilton; MARCONDES, Danilo. Dicionário Básico de Filosofia. 5. ed. Rio de Janeiro: J. Zahar, 2008. Disponível em: https://sites.google.com/site/sbgdicionariodefilosofia/ desvendamento. Acesso em: 18 ago. 2014.

JUSTO, José Sterza. Andarilhos e trecheiros: errâncias e nomadismo na contemporaneidade. 2005. 323f. Tese (LivreDocência) - Faculdade de Ciências e Letras de Assis Universidade Estadual Paulista, Assis, 2005. 
JUSTO, José Sterza; NASCIMENTO, Eurípedes Costa do. Errância e delírio em andarilhos de estrada. Psicol. Reflex. Crit., Porto Alegre, v. 18, n. 2, p. 177-187, ago. 2005. http:// dx.doi.org/10.1590/S0102-79722005000200005

LILIENTHAL, Luiz A.; MORATO, Henriette, T. P. Metodologia utilizada em uma oficina de recursos expressivos. In: CUPERTINO, Christina Menna Barreto. (Org). Espaços de criação em Psicologia: oficinas na prática. São Paulo: Annablume, 2008. p. 93-121.

OSTRONOFF, Vera Helena; FÁVERO, Cacilda B.; BALDIN, Paola D. Uma experiência de supervisão em oficinas de criatividade. In: CUPERTINO, Christina Menna Barreto (Org.). Espaços de criação em Psicologia: oficinas na prática. São Paulo: Annablume, 2008. p. 77-94.

PESSANHA, Juliano Garcia. Ensaio II. In: Ignorância do Sempre. São Paulo: Ateliê, 2000. p. 101-121. 